\title{
Accommodating individuals with traumatic brain injury: An analysis of employer-initiated cases handled by the Job Accommodation Network
}

\author{
D.J. Hendricks* and Elaine Sampson \\ West Virginia University, Morgantown, WV, USA
}

Received 3 April 2017

Accepted 12 May 2017

\begin{abstract}
.
BACKGROUND: The Job Accommodation Network (JAN) has provided customized accommodation information to employers, individuals with disabilities, and their representatives (e.g., family, rehabilitation counselors, union representatives) since 1983. For each inquiry where such information is sought, detailed records are maintained regarding the type of inquiries made and the information provided.

OBJECTIVE: The objective of the current study is to present a descriptive analysis of the employer-initiated cases related to Traumatic Brain Injury (TBI) handled by the accommodation specialists at JAN during the five years from 2012 through 2016.

METHODS: Records related to instances of TBI as recorded by the JAN accommodation specialists were reviewed. Information pertaining to the type of business, occupational category, limitations being experienced by the individual, and issues discussed with the accommodation specialist are presented.

RESULTS: The type of businesses and the occupational categories indicated by the employer were broad ranging, although there was a preponderance of cases in the area of Public Administration. Limitations related to cognition were the most frequent for which employers sought accommodation information. The largest category for the type of issues discussed was related to the Americans with Disabilities Act and other disability-pertinent legislation.

CONCLUSIONS: The incidence of employers seeking accommodation information for individuals who have incurred a TBI is very low (0.5\%). Findings support those of other authors such as Ponsford and Spitz (2015), in that accommodation information was most frequently requested for individuals in professional (i.e., office-type jobs), rather than for laborer positions.
\end{abstract}

Keywords: Business type, job type, employers

\section{Introduction}

According to the Centers for Disease Control and Prevention (CDC) [1], approximately 2.8 million people incurred a Traumatic Brain Injury (TBI) in

*Address for correspondence: D.J. Hendricks, PO Box 6080, Morgantown, WV 26506-6080, USA. E-mail: hendricks@ jan.wvu.edu.
2013. In 2010, it was estimated that approximately 3.17 million people in the United States had a lifelong or long-term disability from TBI [2]. From 2007 to 2013, the number of Emergency Department (ED) TBI related visits increased by $50 \%$ [1]. Outpatient clinics and doctors' offices saw nearly 1.2 million visits that included a TBI diagnosis from 2007 through 2009 [3], and between 2001 and 2012, there were approximately 3.42 million ED visits for sports 
and recreation-related TBI incidences [4]. Of these, approximately $70 \%$ were among people 19 years and younger. Worldwide, TBI is the leading cause of disability in people under the age of 40 , "severely disabling 150-200 people per million annually" [5].

Several recent studies have been published providing systematic reviews of the post-TBI return to work literature [6-8]. Saltychev et al. [6] reviewed 80 studies published in English from 1990 through 2011. They reported "no strong evidence" that rehabilitation interventions impacted employment outcomes. Nor did they identify any characteristics, either pre-injury or post-injury, that reliably predicted employment outcomes following a TBI.

In a smaller-scale review of the literature involving 11 articles and using additional inclusion criteria, Donker-Cools [7] found "strong evidence" for the effectiveness of a specific type of intervention. Whereas the Saltychev et al. review inclusion criteria involved a population of "working-aged adults with TBI," (p. 1516), the Donker-Cool search criteria were limited to, "patients with non-progressive ABI [Acquired Brain Injury], working pre-injury..." (p. 113). These authors found that interventions that incorporated work-directed components in conjunction with education and coaching were efficacious in achieving a return to work outcome. In particular, they noted the importance of being able to return the individual to the same job with the same employer as pre-injury and the willingness of the employer to implement needed workplace accommodations.

Matérne, Lundqvist, and Strandberg [9] interviewed 10 individuals ( 5 men, 5 women) with an ABI who had been able to return to work following their injury. They were able to identify three themes associated with the successful return to employment post-injury: (1) a rehabilitation plan developed with the individual's active participation and customized to their specific needs and desires, (2) a strong motivation to return to work including work that was stimulating and for which they received recognition, and (3) overcoming limitations in communication and cognitive abilities due to the injury. These authors concluded that, when these elements are incorporated into a rehabilitation plan, and the individual receives appropriate support from family, employers, coworkers, and society as a whole, successful return to work is possible.

Although every TBI is different, the typical longand short-term challenges include cognitive, physical, emotional, and behavioral deficits that negatively impact the individual [10]. Ponsford and Spitz [11] also noted these challenges impact the capacity for employment among individuals who incur a TBI while they are young. Cuthbert et al. [3] likewise stated "the adverse outcomes associated with TBI can have a substantial impact on a person's ability to assume gainful employment after injury." One particular area of difficulty noted by Harris et al. [12] involved the inability of individuals with a TBI to accurately recall their previous work history. While they often are able to report prior job titles, details regarding the actual work performed were less reliable.

In the workplace, challenges faced by people with TBI include the inability to adhere to the structure of a typical work environment, challenges with keeping up with the pace of the environment, and stress from work [3]. Because these challenges can impact the ability of a person to successfully work after a TBI, employment status is an important measure of successful rehabilitation and recovery [10]. Cuthbert et al. [3] found that of 93 participants, the probabilities of being employed 1 year post-injury were 95\% lower in participants who were unemployed prior to the injury, $74 \%$ lower for participants with more severe damage, and $82 \%$ lower for participants with more significant cognitive limitations. The rates of employment vary from study to study, but most researchers agree that the rate of unemployment and underemployment increases after a TBI is sustained and that this trend continues over time. In another study [13], $81 \%$ of the participants were employed full-time at the time of injury, but only $45 \%$ were working at the 10 year follow-up mark. This population was still in their most productive years and the authors believed that affected domains were a consideration when looking at long-term and follow-up interventions.

There are many variables that can impact return to work for someone who has incurred a TBI. These include, but are not limited to, pre-injury employment status, severity of injury, age, education, injury-related physical impairments, cause of injury, cognitive impairments, and behavioral and emotional difficulties [11]. Additionally, there has been a change in perception of TBI to that of a chronic condition, rather than as only an injury with short-term consequences. Thinking of TBI as a condition that requires long-term monitoring and care could result in employment-centered rehabilitation opportunities for people with TBI [3].

Ponsford and Spitz [11] further noted that despite $55.9 \%$ of their participants being employed at 1 year 
post-injury, $55.5 \%$ at 2 years post-injury and $58.5 \%$ at three years post-injury, instability in employment is still a significant challenge for people who have experienced a TBI. They found $15.9 \%$ of those employed at the 1 year period were not employed after 3 years, whereas $26 \%$ of those not employed at 1 year were employed at 3 years post-injury. Some of the factors that appeared to lead to stable employment included education and type of employment. When considering type of employment, people with professional jobs were more likely to maintain stable employment than those with laborer jobs [11]. Stable employment not only provides the individual with income, it also has a positive impact on their post-injury psychosocial adjustment, life satisfaction, and quality of life [3]. Studies show that when people with TBI are unemployed at 10 years post-injury, they demonstrate higher levels of anxiety and depression as compared with their employed counterparts [11, 12].

The Cuthbert et al. study [3] found that of all employed people in the United States between the ages of 16-60 who entered inpatient rehabilitation for TBI between 2001 and 2010, only 3.2\% had passed away by 2 years post-injury. Unemployment of the surviving participants, however, was $60.4 \%$ as compared to the national average of only $9 \%$ during approximately the same time period (2003-2013). The descriptive demographic data showed the highest number unemployed post-injury were females, African-Americans, and those with lower education attainment. The differences between unemployment among the TBI population and the general population showed significant differences in rates overall and across comparable groups [3].

Predicting employment stability is achieved through considering both pre- and post-injury factors. These include: demographics, pre-injury employment, injury severity, and level of independence in mobility and self-reported cognitive deficits [11]. Community reentry is compounded by the presence of cognitive, physical and emotional deficits that impact the person with a TBI [2].

The literature to date includes data related to return to work and the stability/ instability of employment, but it does not examine accommodations that were used to assist people with TBI in maintaining competitive employment. The research in the present study examines requests for technical assistance on accommodations initiated by employers that were received by the Job Accommodation Network (JAN) over the past 5 years. JAN is a technical assistance project funded by the US Department of Labor's
Office of Disability Employment Policy (ODEP). JAN's mission is to provide free and confidential information regarding the hiring, retention, training, and promotion of individuals with disabilities in the workplace. Begun in 1983, JAN currently receives more than 55,000 requests for information pertaining to the employment of people with individuals per year from employers, rehabilitation professionals, individuals with a disability, and others. Contact is made via toll-free phone, email, and on-line chat. The information provided by JAN includes, but is not limited to, customized accommodation solutions, assistance understanding rights and responsibilities under various disability-related legislation, and the process of starting and operating a small business. While some of these contacts involve providing limited services such as referral to available federal, state, or local public and private resources, most $(83.5 \%)$ involve JAN personnel conducting a detailed interview to determine specific needs based on the individual's limitation(s) (e.g., seeing, walking, lifting), job (e.g., receptionist, assembly-line worker, truck driver), work environment (e.g., office, manufacturing plan, warehouse), and more.

This paper explores requests for information received by JAN during the past five years from employers that have involved a person with a TBI $(N=216)$. Information is provided regarding the individual's job status, functional limitations, and issues discussed.

\section{Methods}

During the time period of 2012 through 2016, JAN received a total of 243,938 contacts. In $83.5 \%$ of these situations, the person who contacted JAN required specific technical assistance, which resulted in a JAN accommodation specialists conducting a detailed interview in order to determine the appropriate information needs. While these requests historically have been received almost exclusively through JAN's tollfree phone lines, electronic contacts via email and on-line chats are becoming more and more frequent.

In each of these instances, the JAN specialist collects information related to the person making the inquiry (e.g., employer, individual with a disability, friend or family member; business type; business size), about the individual for whom the accommodation information is being sought (e.g., causative factor), limitation(s), and employment status (e.g., job applicant, pre-employment job offer, 
employee), and about relevant job and environmental factors (e.g., office building, warehouse, retail store). JAN specialists respond to inquiries regarding all types of physical and mental causative factors (e.g., vision impairments, paraplegia, multiple sclerosis, schizophrenia, autism, cancer), limitations (e.g., grasping, reading a computer monitor, fatigue, hearing alarm signals), types of businesses (e.g., manufacturing, service industries, construction), and job types (e.g., wait staff, carpenter, data technician, salesperson, corporate executive).

For the current study, JAN's records from 2012 through 2016 (5 years) were searched for cases where the causative factor was a traumatic brain injury. A total of 1,234 such cases were identified during that time period $(0.5 \%)$. Table 1 provides a breakout of the number of contacts and TBI-related instances for each of these 5 years. Of those 1,234 TBI-related inquiries, 215 (17.5\%) were from employers. These employer-initiated cases were then descriptively analyzed across each of the available data fields.

\section{Results}

Employers who requested accommodation information regarding a person with a TBI represented a broad spectrum of business types. Of the 202 employers who provided their business type to the JAN specialist, the largest employer group was public administration $(N=93,46.0 \%)$. This includes the federal government, as well as state and local government. Health care and social assistance employers with $N=29$ (14.4\%) and educational services with $N=23(11.4 \%)$ followed. Table 2 lists the employers' type of business.

The occupation of the individual was provided by 137 of the employers. JAN records this information using the Standard Occupational Classification (SOC) System. The most frequently indicated occupational categories were Office and Administrative Support $(N=31,22.6 \%)$, Management $(N=14$,

Table 1

Total number of contacts received, cases handled, and TBI cases

\begin{tabular}{lrcc}
\hline Year & Contacts & TBI Cases & TBI \% of Contacts \\
\hline 2012 & 41,621 & 277 & $0.7 \%$ \\
2013 & 42,278 & 273 & $0.6 \%$ \\
2014 & 49,164 & 192 & $0.4 \%$ \\
2015 & 55,162 & 230 & $0.4 \%$ \\
2016 & 55,713 & 262 & $0.5 \%$ \\
Totals & 243,938 & 1,234 & $0.5 \%$ \\
\hline
\end{tabular}

$10.2 \%)$, and Business and Financial Operations $(N=12,8.8 \%)$. Table 3 provides a complete listing of the occupational categories indicated by these employers.

Nearly all of the employers who contacted JAN about an individual with a TBI $(N=215,99.5 \%)$ discussed one or more specific limitations with the JAN specialist. In total, 517 limitations were discussed, as presented in Table 4. The most frequent limitations expressed were related to cognitive function with 317 such limitations discussed. Nearly threefourths of the 215 employers who contacted JAN for TBI-related assistance requested information for one or more cognitive limitations $(N=153,71.2 \%)$. Within the Cognition category, memory loss $(N=78)$ and concentration $(N=61)$ were the two most

Table 2

Number of employers by type of business (North American industry classification system)

\begin{tabular}{lrr}
\hline Business Type & $N$ & $\%$ \\
\hline Public Administration & 93 & $46.0 \%$ \\
Health Care and Social Assistance & 29 & $14.4 \%$ \\
Educational Services & 23 & $11.4 \%$ \\
Manufacturing & 12 & $5.9 \%$ \\
Finance and Insurance & 11 & $5.4 \%$ \\
Professional, Scientific, and Technical Services & 9 & $4.5 \%$ \\
Administrative and Support and Waste & & \\
$\quad$ Management and Remediation Services & 8 & $4.0 \%$ \\
Information & 6 & $3.0 \%$ \\
Retail Trade & 3 & $1.5 \%$ \\
Other & 8 & $4.0 \%$ \\
\hline
\end{tabular}

Table 3

Occupational categories of the individual with a traumatic brain injury

\begin{tabular}{lrr}
\hline Occupational Category & $N$ & $\%$ \\
\hline Office and Administrative Support & 31 & $22.6 \%$ \\
Management & 14 & $10.2 \%$ \\
Business and Financial Operations & 12 & $8.8 \%$ \\
Education, Training, and Library & 8 & $5.8 \%$ \\
Production & 8 & $5.8 \%$ \\
Transportation and Material Moving & 8 & $5.8 \%$ \\
Community and Social Services & 7 & $5.1 \%$ \\
Healthcare Practitioner and Technical & 7 & $5.1 \%$ \\
Sales and Related & 6 & $4.4 \%$ \\
Computer and Mathematics & 5 & $3.6 \%$ \\
Protective Service & 5 & $3.6 \%$ \\
Architecture and Engineering & 4 & $2.9 \%$ \\
Healthcare Support & 4 & $2.9 \%$ \\
Installation, Maintenance, and Repair & 4 & $2.9 \%$ \\
Art, Design, Entertainment, Sports, and Media & 3 & $2.2 \%$ \\
Building and Grounds Cleaning and Maintenance & 3 & $2.2 \%$ \\
Construction and Extraction & 3 & $2.2 \%$ \\
Food Preparation and Service-Related & 2 & $1.5 \%$ \\
Life, Physical, and Social Sciences & 2 & $1.5 \%$ \\
Legal & 1 & $0.7 \%$ \\
\hline
\end{tabular}


Table 4

Limitations discussed with employers during TBI-related cases

\begin{tabular}{lrc}
\hline Limitation Category/Specific Limitation & $N$ & $\begin{array}{c}\text { \% of Limitations } \\
\text { Discussed }\end{array}$ \\
\hline Cognition & 317 & $61.3 \%$ \\
Attentiveness/Concentration & 61 & \\
Learning & 47 & \\
Memory Loss & 78 & \\
Organizing/Planning/Prioritizing & 37 & \\
Managing Time & 25 & \\
Other Cognitive Limitation & 69 & $12.4 \%$ \\
Behavioral & 64 & \\
Stress Intolerance & 25 & \\
Inappropriate/Disruptive/Inconsistent Behavior & 16 & \\
Emotional Control & 10 & \\
Other Behavioral Limitation & 13 & \\
Motor & 49 & $3.5 \%$ \\
Decreased Stamina/Fatigue & 19 & \\
Other Motor Limitation & 30 & \\
Sensory & 16 & \\
Vision & 9 & \\
Hearing & 4 & \\
Other Sensory Limitation & 3 & \\
Other & 50 & \\
Not Specified & 21 & \\
Total & 517 & \\
\hline
\end{tabular}

Table 5

Most frequently raised issues by employers

\begin{tabular}{lcr}
\hline Issue & $N$ & $\%$ \\
\hline $\begin{array}{l}\text { Issues related to the ADA, the ADA } \\
\quad \text { Amendments Act, the Rehabilitation Act, }\end{array}$ & 171 & $35.3 \%$ \\
$\quad$ or other disability-related legislation & & \\
$\quad$ Issues regarding the accommodation process & 59 & $12.2 \%$ \\
Determining undue hardship and reasonable & 57 & $11.8 \%$ \\
$\quad$ accommodation & & \\
Job Reassignment & 41 & $8.4 \%$ \\
Leave and/or attendance & 35 & $7.2 \%$ \\
Determining and/or altering essential & 23 & $4.7 \%$ \\
$\quad$ functions of a position & & \\
$\quad$ Meeting production standards & 21 & $4.3 \%$ \\
Job restructuring & 18 & $3.7 \%$ \\
Other Issues & 60 & $12.4 \%$ \\
Total & 485 & \\
\hline
\end{tabular}

frequently cited limitations. The second most frequently discussed limitation category was Behavioral limitations $(N=64)$, with stress intolerance $(N=25)$ being the specific limitation most often noted by employers. In 25 (11.6\%) instances, both cognitive and behavioral limitations were reported.

Employers requested information pertaining to a total of 771 specific issues. Examining those cases from employers who specifically indicated the individual was experiencing a cognitive limitation, 153 employers reported a total of 485 issues for which they were seeking technical assistance. In half of these cases $(N=109$ out of $215,50.7 \%)$, these issues were regarding a person currently working for the employer, rather than for some who had applied for or who was being considered for a job. Frequently raised issues, as provided by the employers, are listed in Table 5.

\section{Conclusions}

The number of requests for technical assistance that are initiated by the employer to the Job Accommodation Network involving a TBI is surprisingly low $(0.5 \%)$ and are primarily requested for individuals involved in office-type duties, management, and business operations. The preponderance of employers in the area of public administration also is interesting. It is not surprising that the most frequently indicated limitations involved cognitive functioning $(61.3 \%)$ and behaviors such as stress intolerance and inappropriate behaviors (12.4\%). What is, perhaps, more surprising is the number of cases that involved requests for technical assistance regarding legislated requirements. The Americans with Disabilities Act has now been in effect for more than 25 years; the Rehabilitation Act for far longer (since 1973). Yet, employers still frequently need assistance in understanding the specific terms (e.g., undue hardship), rights and responsibilities, and other aspects of these laws. 
The findings from this study support those of Ponsford and Spitz [7], in that $22.6 \%$ of the JAN instances were for individuals in Office and Administrative Support positions, $10.2 \%$ in Management, and $8.8 \%$ in Business and Financial Operations. Far fewer JAN cases were received during the 5 years studied for individuals engaged in Food Preparation and Service-Related jobs (2.2\%), Sales and Related jobs (4.4\%), and Installation, Maintenance, and Repair jobs (2.9\%). As noted by Ponsford and Spitz [7], employment was more stable for persons with a TBI who were in professional jobs, as compared to those in laborer positions.

In conclusion, employers are not seeking accommodations for individuals with TBIs working in otherwise commonplace employment settings such as fast-food service and retail sales. While it may be that employers in these types of businesses are able to accommodate individuals who have experienced a TBI without the need for the technical assistance provided by JAN, it also is possible they are not hiring people with a TBI due to the availability of a large potential pool of applicants who would not necessitate making accommodations and changes to their standard business practices. Additional research may well provide these answers.

There are a number of limitations to the current study. First, it must be noted that use of the Job Accommodation Network service is voluntary. For the most part, employers who request information already have taken the first step by understanding the value workplace accommodations can make in improving the ability of a person with a disability to effectively perform his or her job. Second, the present study does not include the solutions discussed with employers by the specialists at the Job Accommodation Network regarding accommodating individuals who have experienced a TBI. This will necessitate a large-scale qualitative analysis which will be conducted and the results reported in a future article. Third, many of the JAN cases identified as involving a person with a TBI could not be used because they lacked sufficient data. Those who use JAN are not required to provide their information and many prefer to use the service anonymously.

\section{Conflict of interest}

None to report.

\section{References}

[1] Center for Disease Control and Prevention [Internet]. Atlanta, GA: Traumatic Brain Injury and Concussion: Get The Facts [cited 2017 May 24]. Availabe from https:// www.cdc.gov/traumaticbraininjury/get_the_facts.html

[2] Gary KW, Ketchum JM, Arando-Lasprilla J, Kreutzer JS, Novack T, Copolollo A, Deng X. Differences in employment outcomes 10 years after traumatic brain injury and ethnic minorities. Journal of Vocational Rehabilitation 2010; 33(1):65-75.

[3] Cuthbert JP, Harrison-Felix C, Corrigan JD, Bell JM, Haarbauer-Krupa JK, Miller A. Unemployment in the United States after traumatic brain injury for workingage individuals: Prevelance and associated factors 2 years postinjury. Journal of Head Trauma Rehabilitation 2015; 30(3):160-74

[4] Coronado VG, Tadesse H, Cheng TA, Bell JM, HaarbauerKrupa J, Lionbarger MR, Flores-Herrera J, McGuire LC, Gilchrist J. Trends in sports- and recreation-related traumatic brain injuries treated in US emergency departments: The national electonic injury surveillance system - all injury program (NEISS-AIP) 2001-2012. Journal of Head Trauma Rehabilitation 2015;30(3):185-97.

[5] De Silva MJ, Roberts I, Perel P, Edwards P, Kenward MG, Fernandes $\mathrm{J}$, ... Patel V. Patient outcome after traumatic brain injury in high- middle- and low-income countries: Analysis of data on 8927 patients in 46 countries. International Journal of Epidemiology 2009;38(2):452-7.

[6] Saltychev M, Eskola M, Tenovuo O, Laimi K. Return to work after traumatic brain injury: Systematic reivew. Brain Injury 2013;27(13-14):1516-27.

[7] Donker-Cools BHPM, Daams JG, Wind H, FringsDresen MHW. Effective return-to-work interventions after acquired brain injury: A systematic review. Brain Injury 2016;30(2):113-31.

[8] van Velzen JM, van Bennekom CAM, Edelaar MJA, Sluiter JK, Frings-Dresen MHW. How many people return to work after acquired brain injury?: A systematic review. Brain Injury 2009;23(6):473-88

[9] Matérne M, Lundqvist L, Strandberg T. Opportunities and barriers for successful return to work after acquired brain injury: A patient perspective. Work 2017;56:125-34.

[10] Andelic N, Stevens LF, Sigurdardottir S, Arango-Lasprilla $\mathrm{J}$, Roe C. Associations between disability and employment 1 year after traumatic brain injury in a working age population. Brain Injury 2012;26(3):261-9.

[11] Ponsford JL, Spitz G. Stability of employment over the first 3 years following traumatic brain injury. Journal of Head Trauma Rehabilitation 2015;30(3);E1-11.

[12] Harris JE, Mays J, Ratcliff G, Chase S, Vemich L, Colantonio A. Level of agreement of occupational titles between persons with traumatic brain injury and their informants. Work 2016;53(3):561-7.

[13] Andelic N, Hammergren N, Bautz-Holter E, Sveen U, Brunborg C, Roe C. Functional outcome and health-related quality of life 10 years after moderate-to-severe traumatic brain injury. Acta Nuerologica Scandinavia 2009;120(1): 16-23. 